\title{
The Hardness and Corrosion Properties of Trivalent Chromium Hard Chromium
}

\author{
Jiazhu Li ${ }^{*}$, Yanjing Li², Xiaohua Tian², Ling Zou², Xing Zhao², Sanfeng Wang², Shenggang Wang3 \\ ${ }^{1}$ Beijing Blue Chemicals Centre, Beijing, China \\ ${ }^{2}$ Prof. Jiazhu Li Laboratory, Wuhan Desytek Environment Protection \& New Materials Co, Ltd, Wuhan, China \\ ${ }^{3}$ Institute of Metal Research, Chinese Academy Sciences, Beijing, China \\ Email: *bluechem@126.com
}

How to cite this paper: Li, J.Z., Li, Y.J., Tian, X.H., Zou, L., Zhao, X., Wang, S.F. and Wang, S.G. (2017) The Hardness and Corrosion Properties of Trivalent Chromium Hard Chromium. Materials Sciences and Applications, 8, 1014-1026.

https://doi.org/10.4236/msa.2017.813074

Received: September 30, 2017

Accepted: December 8, 2017

Published: December 11, 2017

Copyright (c) 2017 by authors and Scientific Research Publishing Inc. This work is licensed under the Creative Commons Attribution International License (CC BY 4.0).

http://creativecommons.org/licenses/by/4.0/

\begin{abstract}
The formulation of hard chromium plating from trivalent chromium electrolyte and its related process have been intensively studied in this work. Through optimized conditions, the coating hardness can achieve more than $\mathrm{HV}_{0.1} 900$ without any treatment and $\mathrm{HV}_{0.1} 1700$ after heat treatment for five minutes at $300^{\circ} \mathrm{C}$, and the thickness of hard chromium coating was about 100 $\mu \mathrm{m}$. The hard chromium coatings show good adhesion on the carbon steel and low alloy structural steel. The corrosion resistance of hard chromium coatings was enhanced by the adding nanometer materials into trivalent chromium plating coatings. More than 120 hours salt spray corrosion resistance can be achieved with 40 to 50 microns thickness of trivalent chromium plating coatings.
\end{abstract}

\section{Keywords}

Corrosion Resistance, Nanometer Materials, Hard Chromium, Trivalent Chromium

\section{Introduction}

Hard chromium as the functional electroplating coatings has been widely used for equipment manufacturing, such as automotive, hydraulic components, industrial roll and heavy-duty machine tools, etc. [1] [2]. Hexavalent chromium has been used as the main solution composition of hard chromium plating as hexavalent chromium plating process stability and plating quality are reliable up to now [3]. However, it is well known that hexavalent chromium is hazardous and serious environmental pollutant. Hexavalent chromium has been restricted to use due to the enhanced consciousness of environmental protection and related 
laws issued by many countries. Many solutions have been proposed to remove toxic chromium from electroplating wastewater [4]. However, it is very necessary to replace hexavalent chromium plating with trivalent chromium plating [5]. It is very interesting to be noted that trivalent chromium plating hard chromium is the most promising alternative solution as the replacement of hexavalent chromium. Hard chromium plating coatings has been extensively studied for more than one century [6] [7].

The hard chromium plating coatings with 60 microns thick have been reported, and the various factors associated with the trivalent chromium performance and related process have been investigated [8]. For example, the trivalent chromium plating hard chromium coatings were applied on vehicle parts, printing roller, and worm [9] [10]. Ni-W electrodeposits have emerged as one of the most suitable alternatives to hard chromium mainly owing to their remarkable mechanical, tribological properties, and minor changes in wear resistance and corrosion performance [11]. The hardness of pure $\mathrm{Cr}$ coating prepared directly from trivalent chromium sulfate electrolyte is up to $900 \mathrm{HV}$ without any other processing, its thickness and grain size are about $30 \mu \mathrm{m}$ and $10-20 \mathrm{~nm}$ respectively, the adhesion between the coating and the substrate is about $139.6 \mathrm{~N}$ and the corrosion resistance of the substrate is improved significantly by the deposited Cr coating [12]. Effect of pulsed electrodepostion on hardness was investigated for the $\mathrm{Cr}-\mathrm{C}$ electrodeposits obtained from a trivalent chromium bath, the hardness and wear parameters of the electrodeposits may be sufficiently improved when using pulsed current. For instance, at $\mathrm{t}(\mathrm{on})=\mathrm{t}(\mathrm{off})=1 \mathrm{~s}$, the hardness reaches the values of similar to 1200 divided by $1300 \mathrm{HV}$ (meanwhile, it is close to 850 divided by $950 \mathrm{HV}$ at a steady-state electrolysis) [13]. The coatings obtained from a sulfate trivalent chromium bath containing formic acid exhibit particular electrochemical behavior (absence of the active dissolution range in acid solution), the hardness of these coatings does not differ noticeably from that typical of coatings obtained in Cr (VI)-based baths [14]. The hardness, corrosion and wear resistances of chromium-tungsten carbide composite coatings obtained by suspending different concentrations of WC particles in a trivalent chromium plating solution shows better performance compared with the chromium-free deposit [15]. The hardness of electroplated Cr-C alloy coatings from a trivalent chromium bath and hard $\mathrm{Cr}$ coatings electrodeposited from conventional hexavalent chromium bath increases and decreases with the increase in annealing temperature. The as-deposited $\mathrm{Cr}$ - $\mathrm{C}$ alloy coatings exhibited better corrosion resistance than the conventional Cr coatings [16].

In this work, we studied the hardness and corrosion properties of trivalent chromium hard chromium coating. We found that its hardness and corrosion resistance were evidently improved, and that the possible factors responsible for these results were also be proposed. In this article, extensive research has been studied on the improvement of the trivalent chromium hard chromium corrosion resistance and its stability of the plating solution in the mass production process. 


\section{Experimental Methods}

\subsection{Trivalent Hard Chromium Plating Test}

The volume of plating solution is $200 \mathrm{~L}$, anode and cathode are DSA insoluble anode and 45\# carbon steel bars with $\Phi 32 \mathrm{~mm}$ and $20 \mathrm{~cm}$ in length, respectively. The area of covering cathode is $1.6 \mathrm{dm}^{2}$. The current, potential, temperature, time and current density are $50 \mathrm{~A}, 12 \mathrm{~V}, 45^{\circ} \mathrm{C}, 120 \mathrm{~min}$ and $30 \mathrm{~A} / \mathrm{dm}^{2}$, respectively. The thickness and micro-hardness of thin film were measured by Portable Thickness Gauge (Fischer, mop) and micro-hardness Tester (Shanghai Jiving Precision, HV-10001S, the load is $100 \mathrm{~g}$ ), respectively. The salt spray test and the measurement of grain size were carried out by Salt Spray Tester (Dungun Xebio, XB-OTS-90) and Metallographic Microscope (Instrument Manufacturing Co., 4X-CIS), respectively. The differential scanning calorimetry (DSC) of thin film was measured by NETZSCH-Gerätebau GmbH (STA-449C).

\subsection{The Stability Test of Trivalent Hard Chromium Solution}

Adopt the method of continuous plating, until the solution was unable to plating, then adjust back to the normal usage situation, study the stability of the solution performance. Adopt the method of continuous plating, until the solution was unable to plating, then adjust back to the normal usage situation, study the stability of the solution performance. It must be ensuring that a new process in production can be stable for a long time. Plating test of trivalent hard chromium solution was carried out as the following steps. Solution: 2 cups of $1.6 \mathrm{~L}$; Anode: DSA insoluble anode, $150 \times 60 \mathrm{~mm} \times 2$ pieces; Cathode: copper bar, $\Phi 8 \mathrm{~mm}$, immersed in the plating solution length is $8 \mathrm{~cm}$, covers an area of $0.2 \mathrm{dm}^{2} ; \mathrm{I}=6$ $\mathrm{A}, \mathrm{J}=30 \mathrm{~A} / \mathrm{dm}^{2}, \mathrm{~T}=40^{\circ} \mathrm{C}$. The rectifier is described as Table 1 .

\subsection{Destruction Tests of Plating Solution}

By electroplating copper bar continuously, the only trivalent chromium was added in the solution, the destruction test was carried out, until it experienced 150 ampere-hours/L, the performance of plating bath was as shown in the Hull specimens (left), after adding additional agent, Hull specimen (right) showed the plating recovered well, the plating solution showed good restore ability (Figure $1)$.

\subsection{Terminal Life Test of Plating Solution}

By continuous electroplating copper bar while adding additional agent, we assess the terminal life of the trivalent hard chromium solution. Table 2 shows the change of tank pressure and current density in different electroplating time,

Table 1. Test equipment list.

\begin{tabular}{cccc}
\hline No. & Instrument & Manufacturer & Type \\
\hline 1 & DC Rectifier & Fushun Yingke & YK-3050 \\
\hline
\end{tabular}




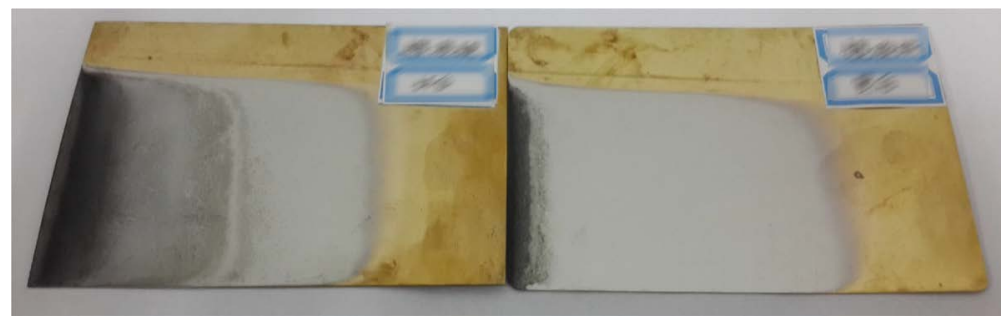

Figure 1. Hull specimen of trivalent chromium plating.

Table 2. Test condition.

\begin{tabular}{cccc}
\hline No. & Plating time $(\mathrm{Ah} / \mathrm{L})$ & Current density $\left(\mathrm{A} / \mathrm{dm}^{2}\right)$ & Tank pressure $(\mathrm{V})$ \\
\hline 1 & 0 & 30 & 28 \\
2 & 100 & 30 & 23.4 \\
3 & 200 & 20 & 19.9 \\
4 & 300 & 10 & 19.7 \\
5 & 430 & 5 & 19.8 \\
\hline
\end{tabular}

from left to right, from top to bottom, followed by electroplating time 0,100 $\mathrm{Ah} / \mathrm{L}, 200 \mathrm{Ah} / \mathrm{L}, 300 \mathrm{Ah} / \mathrm{L}, 430 \mathrm{Ah} / \mathrm{L}$. Longer duration of electroplating, high area of the plating gradually becomes poor. When electroplating time is 430 $\mathrm{Ah} / \mathrm{L}$, on high area of the Hull specimen, the burning phenomenon is serious. And the working current density can only reach $5 \mathrm{~A} / \mathrm{dm}^{2}$, reaching the limit of plating solution life.

\subsection{The Measurement of Hardness and the Characterization of Corrosion Properties}

The loading of micro-hardness tester is $100 \mathrm{~g}$ (HV0.1), force duration for $10 \mathrm{~s}$. The specimens with trivalent hard chromium coatings were heat treated at temperature $100^{\circ} \mathrm{C}, 200^{\circ} \mathrm{C}$ and $300^{\circ} \mathrm{C}$ respectively, heat preservation for 2 hours. After cooling to room temperature, the hardness tests were carried out. The differential thermal analysis for the specimen was carried out.

\section{Results and Discussion}

\subsection{Metallographic and Hardness Test of the Trivalent Chromium Plating Hard Chromium}

The metallographic image along the cross section of coating was shown in Figure 2, the thickness of trivalent hard chromium coating is over 100 microns. The hardness of trivalent hard chromium coating was $\mathrm{HV}_{0.1} 950$. With the increase of temperature, macroscopic crack on the surface of the specimen will be more obvious, may be due to release internal stress of the coating. With the increase of heat treatment temperature, the hardness of coating gradually rises. The hardness value rises significantly up to HV1800 when heat treatment temperature was $200^{\circ} \mathrm{Cand} 300^{\circ} \mathrm{C}$.Maybe when temperature rises, amorphous or nanocrystals of chromium changes to the crystalline state, so that the hardness increases 
greatly. The hardness of basic material went down slightly fast as the up of temperature, but not obvious. It may be having the wide industrial application. The result was shown as Table 3 and Figure 3.

The average thickness of coatings is about 20 microns; the micrographs of specimens are shown as following figures (Figures 4-7). After heat treatment, the picture shows images (400x) after the determination of hardness. The upper layer is trivalent coating, the lower layer is the base material (45 \# steel).

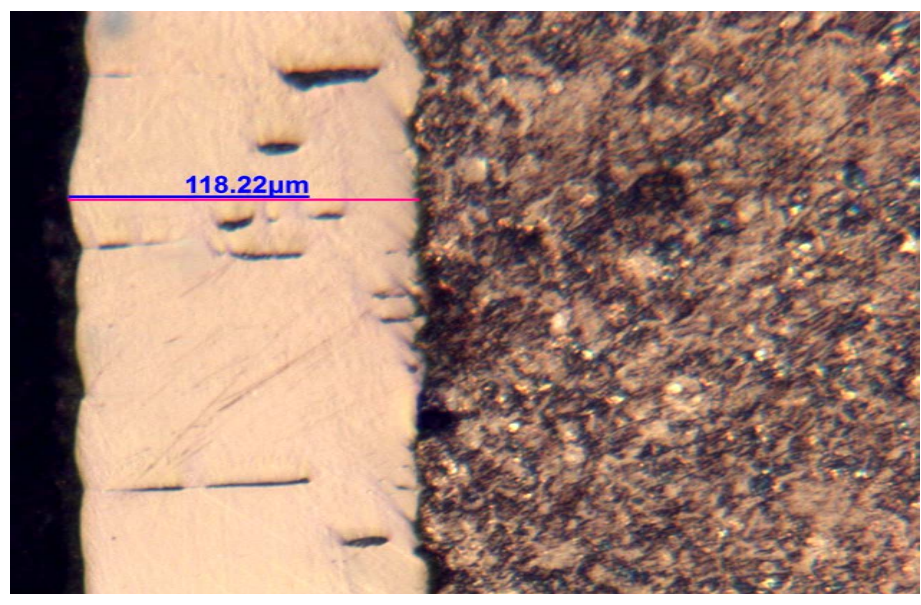

Figure 2. Micrograph of trivalent hard chromium coating (200x).

Table 3. Hardness $\left(\mathrm{HV}_{0.1}\right)$ of specimen heat treated at different temperature.

\begin{tabular}{cccccc}
\hline No. & $\mathrm{T} /{ }^{\circ} \mathrm{C}$ & Without heat treatment & $100^{\circ} \mathrm{C}$ & $200^{\circ} \mathrm{C}$ & $300^{\circ} \mathrm{C}$ \\
\hline 1 & Average coating hardness & 991 & 1050 & 1769 & 1803 \\
2 & Substrate average hardness & 187 & 212 & 210 & 226 \\
\hline
\end{tabular}

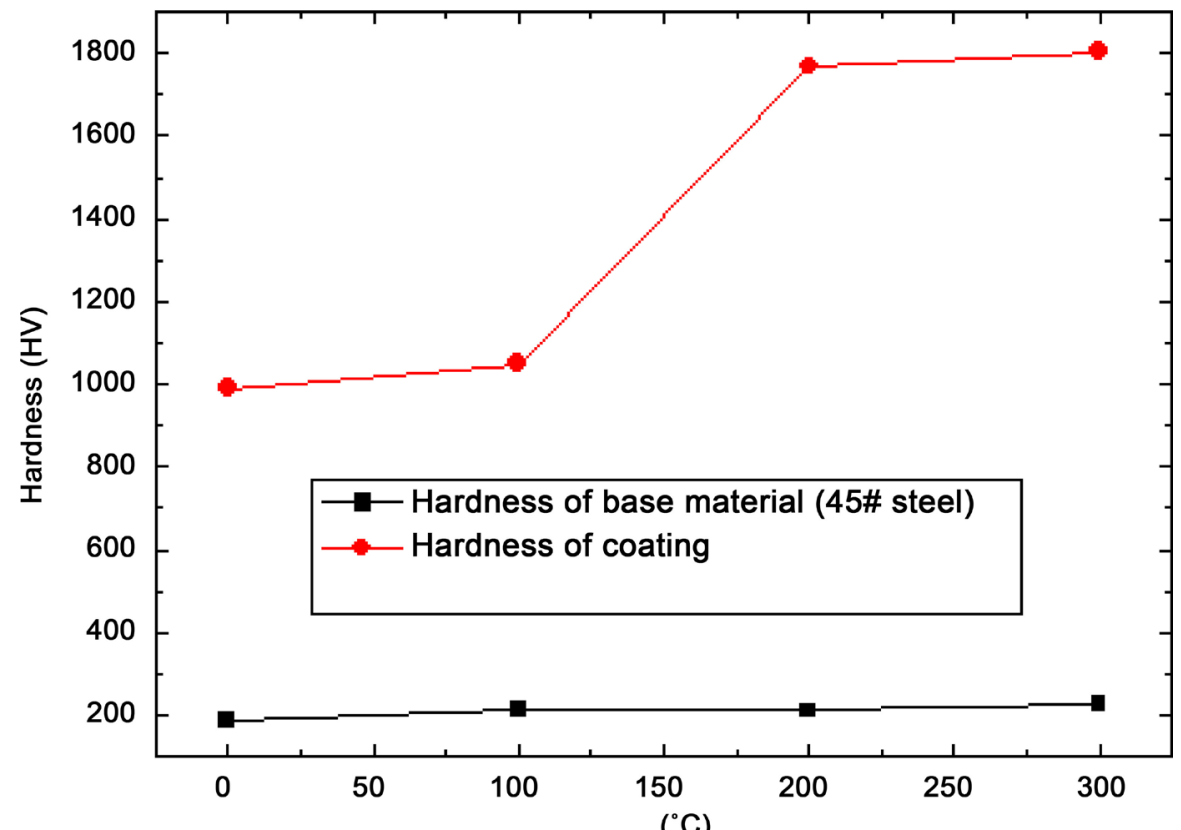

Figure 3. Hardness of specimens change with the temperature of heat treatment. 


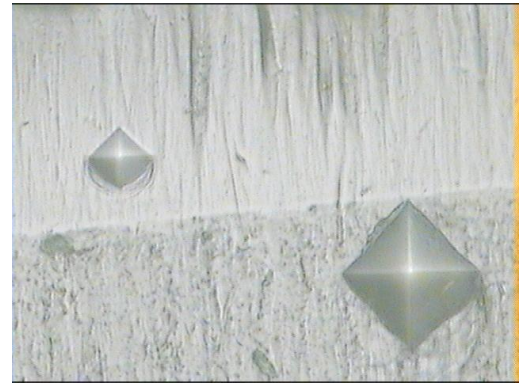

Figure 4. Without heat treatment.

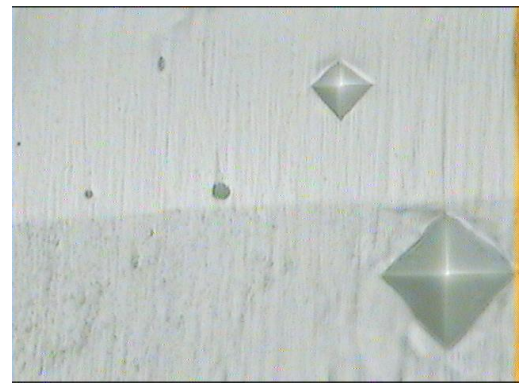

Figure 5. After heat treatment at $100^{\circ} \mathrm{C}$.

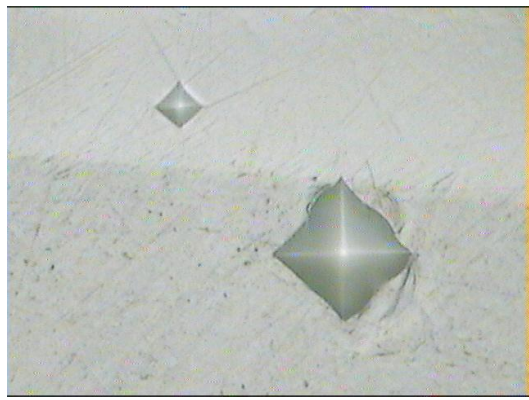

Figure 6. After heat treatment at $200^{\circ} \mathrm{C}$.

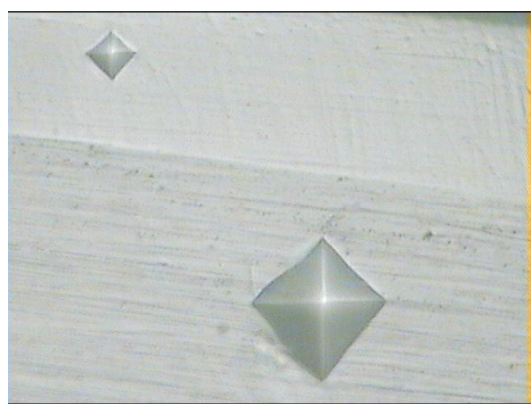

Figure 7. After heat treatment at $300^{\circ} \mathrm{C}$.

\subsection{Terminal Life of Plating Solution and the Influence of Sodium Sulfate on Plating Solution}

By continuous electroplating copper bar while adding additional agent, we assess the terminal life of the trivalent hard chromium solution. Table 4 shows the change of tank pressure and current density in different electroplating time, and the Hull Specimens corresponding as shown in Figure 3: from left to right, 
Table 4. The relationship between the tank pressure and the concentration of sodium sulfate.

\begin{tabular}{cccccccccccccc}
\hline NO. & $\mathbf{1}$ & $\mathbf{2}$ & $\mathbf{3}$ & $\mathbf{4}$ & $\mathbf{5}$ & $\mathbf{6}$ & $\mathbf{7}$ & $\mathbf{8}$ & $\mathbf{9}$ & $\mathbf{1 0}$ & $\mathbf{1 1}$ \\
\hline $\begin{array}{c}\text { Sodium sulfate } \\
\text { (g/L) }\end{array}$ & $\begin{array}{c}\text { original } \\
\text { solution }\end{array}$ & 10 & 30 & 50 & 70 & 100 & 150 & 200 & 250 & 300 & 350 \\
Tank pressure & 25.2 & 28.0 & 26.4 & 25.3 & 24.8 & 23.3 & 22.1 & 21.3 & 21.3 & 21.3 & 21.7 \\
\hline & & & & & & & & & & & & &
\end{tabular}

Remark: from top to bottom, from left to right, the concentrations of sodium sulfate $(\mathrm{g} / \mathrm{L})$ respectively are $0,10,30,50,70,100,150,200,250,300$, and 350 .

Figure 8. Hull specimen of trivalent chromium plating.

from top to bottom, followed by electroplating time $0,100 \mathrm{Ah} / \mathrm{L}, 200 \mathrm{Ah} / \mathrm{L}, 300$ $\mathrm{Ah} / \mathrm{L}, 430 \mathrm{Ah} / \mathrm{L}$. Longer duration of electroplating, high area of the plating gradually becomes poor. When electroplating time is $430 \mathrm{Ah} / \mathrm{L}$, on high area of the Hull specimen, the burning phenomenon is serious. And the working current density can only reach $5 \mathrm{~A} / \mathrm{dm}^{2}$, reaching the limit of plating solution life. From Table 3, we can know that, the tank pressure of plating solution decreased gradually with the increase of concentration of sodium sulfate. The influence of sodium sulfate was observed by artificially adding the sodium sulfate to the plate solution and the results shows in Table 4 and Figure 8.

When the content of the sodium sulfate by artificially adding is $100 \mathrm{~g} / \mathrm{L}$, the coating has no obvious change. On the other hand, the tank pressure obviously decreased with the increase of sodium sulfate. When the content is $200 \mathrm{~g} / \mathrm{L}$, the tank pressure no longer decreased with the addition of sodium sulfate. When adding sodium sulfate content in the $150 \mathrm{~g} / \mathrm{L}$, the burning and the mist phenomenon of the high coating area became more and more serious with the increase of sodium sulfate. Too much quantity sodium sulfate is the main reason of the decrease of the tank pressure and the burning phenomenon of the high coating area.

\subsection{Cooling Crystallization of Plating Solution}

When plating solution arrive the limit life span, it does not represent that the plating solution should be scrapped. Since too much sodium sulfate is the main 


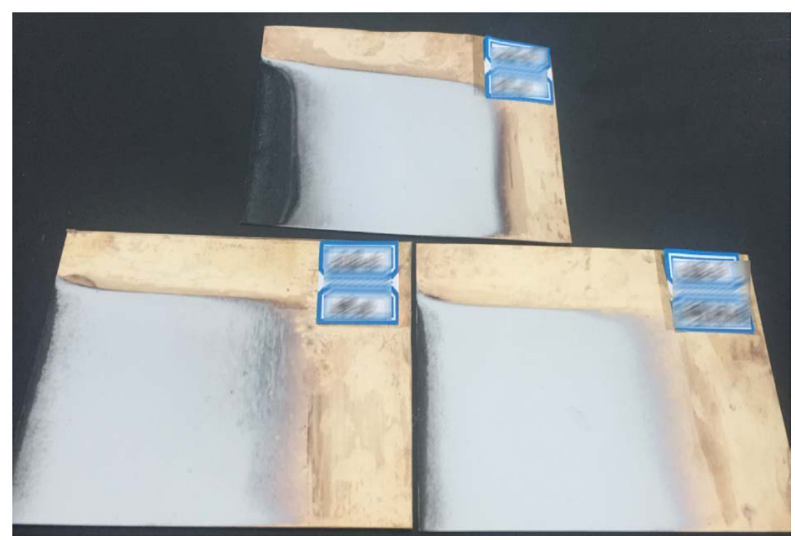

Remark: The upper specimen is before cooling crystallization, the left specimen is after cooling crystallization, the right specimen is the crystallization solution after adjusted.

Figure 9. The plating Hull specimens before and after cooling crystallization.

reason of the burning phenomenon of the high coating area, then we can remove redundant sodium sulfate to restore the plating solution by cooling crystallization when reaching the limit of the life. The Hull specimens are shown as Figure 9 before and after cooling crystallization of solution.

Figure 9 shows that coating is recovered very well by cooling crystallization process, and plating solution can continue to be used. One side, the destruction test showed that the plating solution has the good restore ability. On the other hand, plating solution has a long terminal life which can reach $430 \mathrm{Ah} / \mathrm{L}$ by adding additional agent. In the meantime, plating solution can still be restored when it reached the terminal life by removing the enrichment of conductive salt sodium sulfate. Tank pressure of the plating solution will gradually decline along with the increase of current efficiency, and the enhancement of dispersion and cover ability, so plating solution after working a period of time is better than the new plating solution. So, we can give the conclusion that the stability of trivalent chromium plating solution is very good.

\subsection{The Salt Spray Corrosion Resistances of Trivalent and Hexavalent Chromium Plating}

Trivalent chromium plating hard chromium is amorphous and nanocrystalline, but when the plating stress accumulated to a certain extent, the coating can produce the through cracks. At this time, the electrolyte is easy to through the crack into the basement, which resulting in the formation of micro cell corrosion. The thicker coating is easier to cause through cracks because of the greater stress of coating. So, the increase of the thickness not only can not improve the corrosion resistance of trivalent hard chromium plating, instead, it may lead the decrease of the corrosion resistance because of the wider crack. If nano-meter particles exist in trivalent chromium plating coatings, maybe it can disperse the stress and reduce the cracks, so as to improve the corrosion resistance of coatings. Based on the above reasons, we designed a list of tests to improve corrosion resistance performance of the coatings. 
The salt spray data are shown as Table 5. The salt spray of trivalent chromium coating and hexavalent chromium coating are respectively $0.5 \mathrm{~h}$ and $24 \mathrm{~h}$ when the thickness is $10 \mu \mathrm{m}$ with polished bars which is simulation of roll. When the thickness is $40-50 \mu \mathrm{m}$ with roughen bars, which is simulation of the technology of roll, the salt spray of trivalent chromium and hexavalent chromium coating (adding micro cracks agent) are respectively $1 \mathrm{~h}$ and $72 \mathrm{~h}$. Without the micro cracks agent, the salt spray of $10 \mu \mathrm{m}$ of the hexavalent chromium coating is only $2 \mathrm{~h}$ and $45 \mu \mathrm{m}$ is $30 \mathrm{~h}$. It shows that the thicker is the coatings of hexavalent chromium plating, the better is corrosion resistance. However, the thickness of trivalent chromium coatings does not affect the corrosion resistance at all.

After adding LX in trivalent chromium plating, salt spray of the coatings increases gradually with the increase of coating thickness as Table 6 was shown. But if the coating is too thin, salt fog resistance cannot be improved. The salt spray of original plating solution plating (without LX) does not change with the Change of the thickness of the coating.

\subsection{The Effect Nanometer Additive LX on Corrosion Resistance of Trivalent Chromium Coatings}

The influence on the trivalent chromium coatings corrosion resistance of different

Table 5. The salt spray of the trivalent chromium coating and hexavalent chromium coating.

\begin{tabular}{|c|c|c|c|c|}
\hline No. & Plating solution & Work piece (45 \# steel) & Thickness & Salt spray \\
\hline 1 & trivalent chromium bath & & & $0.5 \mathrm{~h}$ \\
\hline 2 & $\begin{array}{l}\text { hexavalent chromium bath } \\
\text { (micro cracks agent) }\end{array}$ & Polish rods & $10 \mu \mathrm{m}$ & $24 \mathrm{~h}$ \\
\hline 3 & trivalent chromium bath & & & $1 \mathrm{~h}$ \\
\hline 4 & $\begin{array}{l}\text { hexavalent chromium bath } \\
\text { (micro cracks agent) }\end{array}$ & Roughen bars & $40-50 \mu \mathrm{m}$ & $72 \mathrm{~h}$ \\
\hline 5 & hexavalent chromium bath & Polish rods & $10 \mu \mathrm{m}$ & $2 \mathrm{~h}$ \\
\hline 6 & (without micro cracks agent) & Roughen bars & $45 \mu \mathrm{m}$ & $30 \mathrm{~h}$ \\
\hline
\end{tabular}

Table 6. The relation between coating thickness and salt for performance.

\begin{tabular}{ccc}
\hline No. & Coating thickness $(\mu \mathrm{m})$ & Salt spray \\
\hline 1 & 10 & $0.5 \mathrm{~h}$ \\
2 & 20 & $12 \mathrm{~h}$ \\
3 & 28 & $40 \mathrm{~h}$ \\
4 & 43 & $70 \mathrm{~h}$ \\
5 & 53 & $90 \mathrm{~h}$ \\
6 & 68 & 105 \\
7 & 92 & 120 \\
8 & 10 & $0.5 \mathrm{~h}$
\end{tabular}


Table 7. Nanometer additive LX and trivalent chromium coatings.

\begin{tabular}{ccc}
\hline No. & LX content & Salt spray resistance property \\
\hline 1 & $0.2 \%$ & $2 \mathrm{~h}$ \\
2 & $0.5 \%$ & $4-6 \mathrm{~h}$ \\
3 & $1 \%$ & $6-8 \mathrm{~h}$ \\
4 & $1.5 \%$ & $<24 \mathrm{~h}$ \\
5 & $2 \%$ & $24-48 \mathrm{~h}$ \\
6 & $3 \%$ & $32-55 \mathrm{~h}$ \\
7 & $5 \%$ & $48-60 \mathrm{~h}$ \\
8 & $7 \%$ & $96-120 \mathrm{~h}$ \\
9 & $10 \%$ & coating scorc hed \\
10 & Hexavalent chromium (micro cracks agent) & $72-96 \mathrm{H}$ \\
\hline
\end{tabular}

Note: LX is a nanometer material which we made by ourselves.

TG $/ \%$

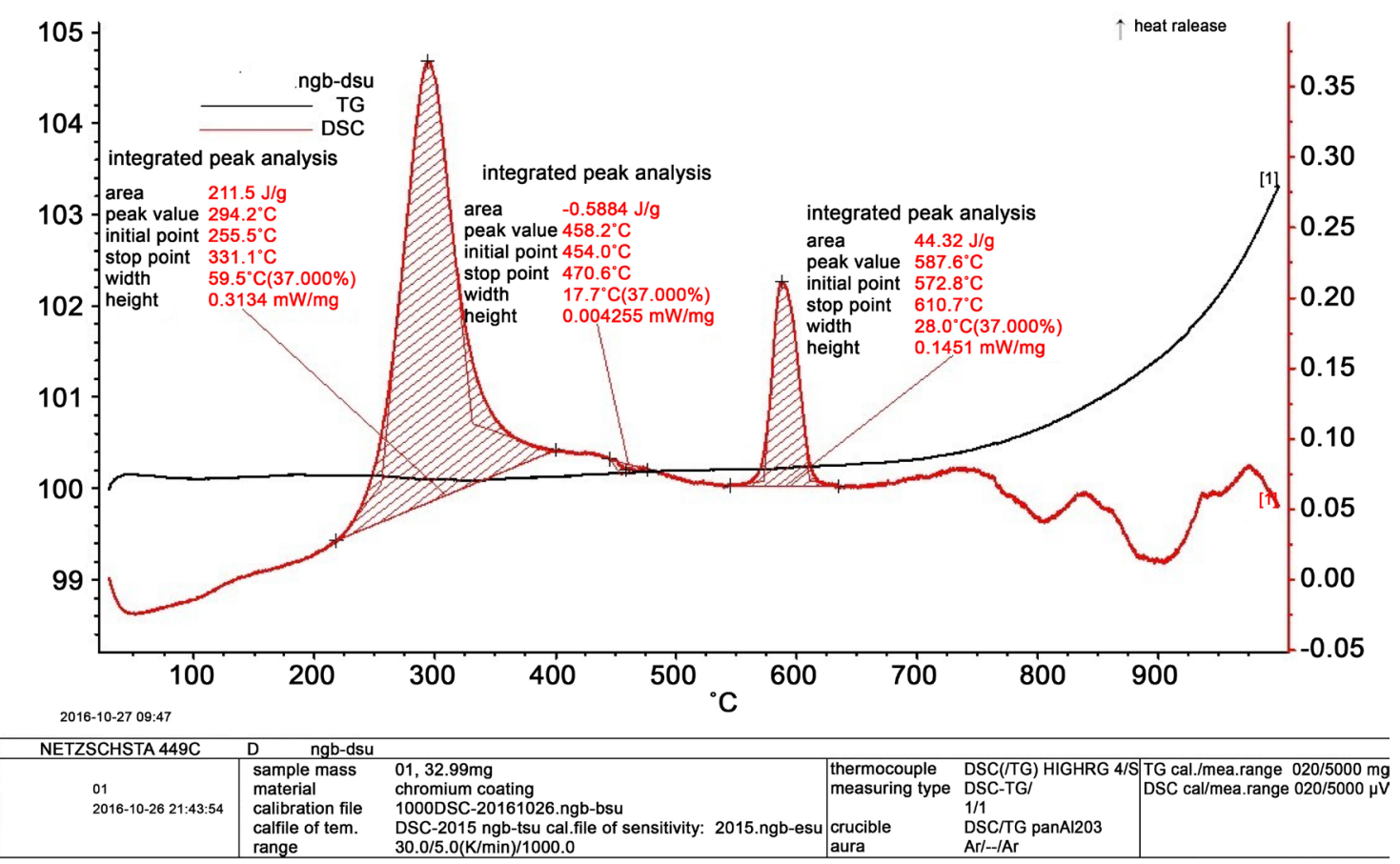

Figure 10. Differential thermal curve.

contents LX (nanometer additive) (roughen iron bars, thickness in $40-50 \mu \mathrm{m}$ ) are shown in Table 7. In the solution with magnetic stirring, the salt spray of trivalent hard chromium coatings increased gradually (up to $96-120 \mathrm{~h}$ ) with the increase of LX content.

\subsection{Differential Thermal Analysis}

The hard chromium coating was prepared from trivalent chromium solution, and then the chromium coating was carried out differential thermal analysis. The DSC curve is shown as Figure 10 . The first peak at about $300^{\circ} \mathrm{C}$ may show 
that the coating has occurred crystal transfer. It is from amorphous to crystal. The second peak at about $600^{\circ} \mathrm{C}$ maybe show that some polymorphism of the coating occurs.

\subsection{The Industrial Application of Trivalent Chromium Hard Chrome Coatings}

The trivalent chromium pilot bath is shown as Figure 11, it has about 200 liters of solution. And the worms, disk hub parts and rear axle with trivalent chromium hard chromium coatings are shown as Figures 12-14.

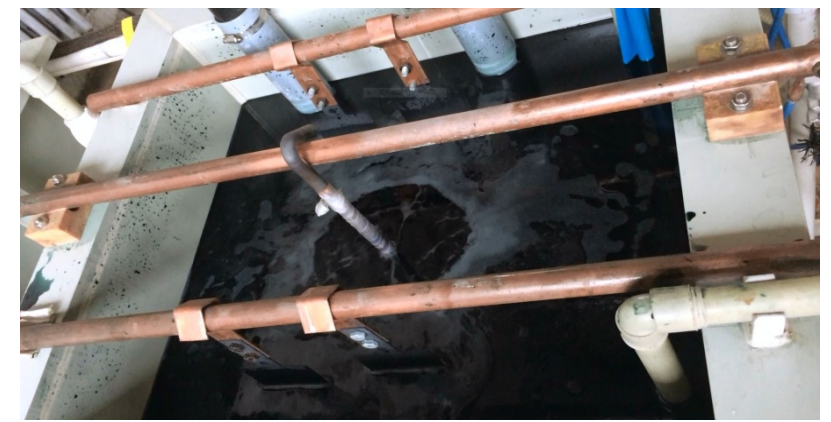

Figure 11. Trivalent chromium bath.

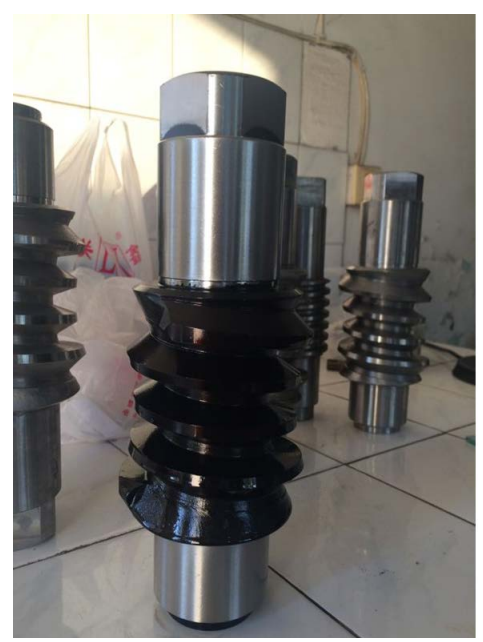

Figure 12. Worms with trivalent chromium hard chromium coatings.

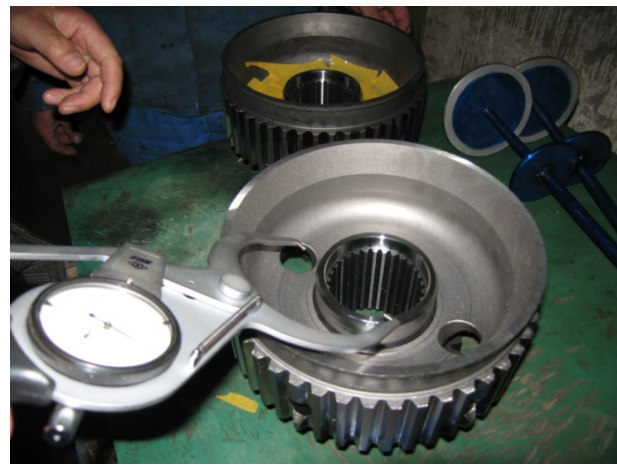

Figure 13. Plating disk hub parts. 


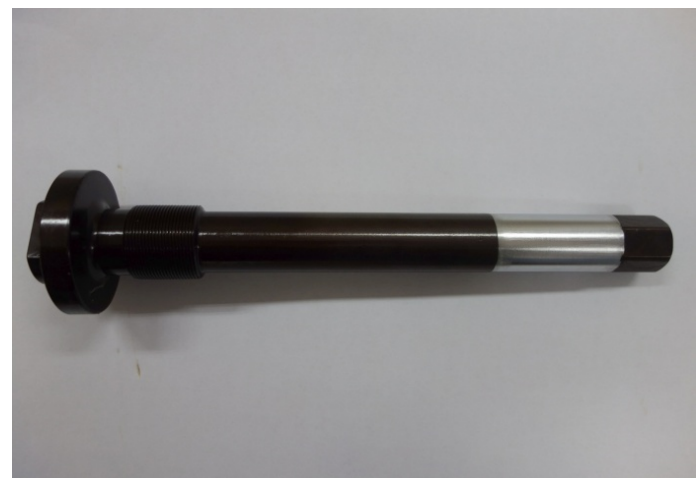

Figure 14. Plating rear axle part.

\section{Conclusion}

More than 100 microns thickness of trivalent chromium plating coatings has been achieved. Moreover, hardness can be more than $\mathrm{HV}_{0.1} 950$, with iridium tantalum DSA anode. After heat treatment, the hardness can be more than $\mathrm{HV}_{0.1} 1700$. The trivalent hard chromium solutions are stable, easy maintenance and continuous plating $430 \mathrm{Ah} / \mathrm{L}$. With nanometer additive, the corrosion resistance of trivalent hard chromium coatings shows obvious improvement.

\section{References}

[1] Kvashnin, A.G., Oganov, A.R., Samtsevich, A.I. and Allahyari, Z. (2017) Computational Search for Novel Hard Chromium-Based Materials. Journal of Physical Chemistry Letters, 8, 755-764. https://doi.org/10.1021/acs.jpclett.6b02821

[2] Liang, A.M., Li, Y.W., Liang, H.Y., Ni, L.W. and Zhang, J.Y. (2017) A Favorable Chromium Coating Electrodeposited from Cr(III) Electrolyte Reveals Anti-Wear Performance Similar to Conventional Hard Chromium. Materials Letters, 189, 221-224. https://doi.org/10.1016/j.matlet.2016.12.022

[3] Castro-Rodriguez, A., Carro-Perez, M.E., Iturbe-Arguelles, R. and Gonzalez-Chavez, J.L. (2015) Adsorption of Hexavalent Chromium in an Industrial Site Contaminated with Chromium in Mexico. Environmental Earth Science, 73, 175-183. https://doi.org/10.1007/s12665-014-3405-4

[4] Liu, S.Q., Mishra, S.B., Zhang, Y. and Qi, L. (2017) Uptake of Hexavalent Chromium in Electroplating Wastewater by Hydrothermally Treated and Functionalized Sand and Its Sustainable Reutilization for Glass Production. ACS Sustainable Chemistry \& Engineering, 5, 1509-1516.

https://doi.org/10.1021/acssuschemeng.6b02185

[5] Liao, C.-W., Lee, H.-B., Hou, K.-H., Jian, S.-Y., Lu, C.-E. and Ger, M.-D. (2016) Characterization of the Cr-C/Si3N4 Composite Coatings Electroplated from a Trivalent Chromium Bath. Electrochemica Acta, 209, 244-253.

https://doi.org/10.1016/j.electacta.2016.05.084

[6] Schopphoven, T., Gasser, A., Wissenbach, K. and Poprawe, R. (2016) Investigations on Ultra-High-Speed Laser Material Deposition as Alternative for Hard Chrome Plating and Thermal Spraying. Journal of Laser Applications, 28, 022501. https://doi.org/10.2351/1.4943910

[7] Li, J.Z., Li, Y.J., Tian, X.H., et al. (2015) Trivalent Research of Progress for Trivalent Chromium Hard Chromium Plating. SUR/FIN, Chicago, 6-8 June. 
[8] Li, J.Z., Mao, Z.L., Ding, Y., et al. (2012) Research of Trivalent Chromium Plating. Plating \& Finishing, 34, 14-17.

[9] Serres, N., Hlawka, F., Costil, S., Langlade, C., Machi, F. and Cornet, A. (2012) Dry Coatings and Eco-Design Part. 1-Environmental Performances and Chemical Properties. Surface \& Coating Technology, 204, 187-196.

https://doi.org/10.1016/j.surfcoat.2009.07.012

[10] Novotnik, B., Zuliani, T., Scancar, J. and Milacic, R. (2012) The Determination of $\mathrm{Cr}(\mathrm{VI})$ in Corrosion Protection Coating by Speciated Isotope Dilution ICP-MS, Journal of Analytical Atomic Spectrometry, 27, 1484-1493. https://doi.org/10.1039/c2ja30111c

[11] Imaz, N., Diez, J.A., Pellicer, E., Sort, J., Grande, H. and Garcia-Lecina, E. (2017) Thermal Treatment Effect on the Mechanical, Tribological and Corrosion Properties of Ni-W Alloy Obtained by Direct and Pulse Plating Electrodeposition. Transactions of the Institute of Metal Finishing, 95, 31-38.

https://doi.org/10.1080/00202967.2017.1260885

[12] Quan, C. and He, Y.D. (2015) Properties of Nanocrystalline Cr Coatings Prepared by Cathode Plasma Electrolytic Deposition from Trivalent Chromium Electrolyte. Surface Coating Technology, 269, 319-323. https://doi.org/10.1016/j.surfcoat.2015.02.001

[13] Protsenko, V.S., Danilov, F.I., Gordiienko, V.O., Baskevich, A.S. and Artemchuk, V.V. (2012) Improving Hardness and Tribological Characteristics of Nanocrystalline Cr-C Films Obtained from Cr(III) Plating Bath Using Pulsed Electrodeposition. International Journal of Refractory Metals \& Hard Materials, 31, 281-283. https://doi.org/10.1016/j.ijrmhm.2011.10.006

[14] Danilov, F.I., Protsenko, V.S., Gordiienko, V.O., Kwon, S.C., Lee, J.Y. and Kim, M. (2011) Nano-Crystalline Hard Chromium Electrodeposition from Trivalent Chromium Bath Containing Carbamide and Formic Acid: Structure, Composition, Electrochemical Corrosion Behavior, Hardness and Wear Characteristics of Deposits. Applied Surface Science, 257, 8048-8053. https://doi.org/10.1016/j.apsusc.2011.04.095

[15] Hamid, Z.A., Ghayad, I.M. and Ibrahim, K.M. (2005) Electrodeposition and Characterization of Chromium-Tungsten Carbide Composite Coatings from a Trivalent Chromium Bath. Surface and Interface Analysis, 37, 573-579. https://doi.org/10.1002/sia.2052

[16] Zeng, Z.X., Wang, L.P., Liang, A.M. and Zhang, J.Y. (2006) Tribological and Electrochemical Behavior of Thick Cr-C Alloy Coatings Electrodeposited in Trivalent Chromium Bath as an Alternative to Conventional Cr Coatings. Electrochemica Acta, 52, 1366-1373. https://doi.org/10.1016/j.electacta.2006.07.038 